\title{
HAROLD BLOOM E OSWALD DE ANDRADE: ANGÚSTIA DA INFLUENNCIA VERSUS ALEGRIA ANTROPOFÁGICA
}

\author{
Sílvio José Stessuk (Letras Vernáculas e Clássicas - UEL)
}

Je est un autre.

ARTHUR RIMBAUD

\section{RESUMO}

No livro Angústia da influência (1973), o crítico literário estadunidense Harold Bloom apresenta a tese de que - grosso modo - a História da Literatura se movimenta quando um autor novo, forte o suficiente, tenta estabelecer, através de sua obra, uma originalidade criativa em face da pressão modelar de um ou mais autores canônicos. Em contraste, o poeta brasileiro Oswald de Andrade, décadas antes, já lançara no Manifesto antropófago ou antropofágico (1928) a idéia, depois detalhada noutros escritos, de que também grosso modo - a relação do autor novo com o que poderia ser chamado de cânone se estabelece através da recepção apropriativa e da digestão crítica deste por aquele. O presente trabalho pretende discutir, a vol d'oiseau, alguns aspectos diferenciadores dessas perspectivas, a possível relação dialética entre elas e as possíveis aplicações respectivas na recepção de um patrimônio cognitivo tradicional e na constru-ção de um patrimônio cognitivo pessoal nos campos da Literatura, da Crítica Literária, da Filosofia e da Educação.

\section{ANGÚSTIA DA INFLUÊNCIA}

Nas décadas recentes, um dos conceitos que mais têm dado azo a debates e estudos no âmbito da Crítica e da Teoria da Literatura é, por certo, o de anxiety of influence - locução que tem sido traduzida em Portugal e depois no Brasil como angústia da influência. Proposto em 1973, pelo scholar estadunidense Harold Bloom, com a publicação de seu livro A angústia da influência - Uma teoria da Poesia, desde então o conceito tem sido burilado pelo crítico numa seqüência de títulos que culmina com $A$ anatomia da influência - Literatura como modo de vi-da, de 2011. Entretanto, o pano de fundo da hipótese de Bloom já estava presente em sua tese de Doutorado, Shelley: engenho de mitos, editada em 1955, que consiste numa revisão da estética romântica, a partir de uma reavaliação da poética de Percy Shelley. Com efeito, vários postulados e atitudes românticas sustentam o perfil do conceito de angústia da influência: o eu, o herói, o amor, a solidão, a melancolia, a busca pela liberdade. Doutro lado, também Friedrich Nietzsche contribui para a formulação do pensamento de Bloom, com a noção de vontade de potência, bem como com determinados matizes do eterno retorno. $\mathrm{E}-$ ainda que o próprio Bloom por vezes o negue - é claramente lícito perceber a sua angústia da influência como uma espécie de tropo literário do complexo de Édipo de Sigmund Freud. Concorrem mais para o conceito, e com importância, a mitologia visionária de William Blake, a Cabala de Isaac Luria via Gershom Scholem, a cosmovisão gnóstica iídiche e diversas outras leituras. Porém, in-vocando-se Shelley, Nietzsche e Freud, já é possível 


\section{SEMINÁRIO DE PESQUISA EM CIÊNCIAS HUMANAS - SEPECH \\ Humanidades, Estado e desafios didático-científicos \\ Londrina, 27 a 29 de julho de 2016}

compreender um pouco o cerne complicado da definição de angústia da influência como sendo, empregando as palavras de Bloom, o "agon" (disputa) "entre poemas, não entre pessoas", suscitado pelo "amor literário, atenuado pela defesa" (BLOOM, 2013, resp. pp. 11, 19 e 21; grifo do autor).

Desse modo, Bloom entende que a História da Literatura se movimenta quando um autor novo, desde que forte o suficiente, tenta estabelecer, através de sua obra, uma originalidade criativa em face da pressão modelar que é exercida pelas obras dos autores canônicos. Noutras palavras: uma vez confrontado com o espectro da tradição literária, cada efebo que ambicione ingressar nessa tradição, a fim de fugir da morte - ou seja, do esquecimento - e se preservar vi-vo "entre os poetas fortes" (id., 1991a, p. 43), inevitavelmente haverá que competir com seus precursores - os heróis que ama - na arena do poema e vir a superá-los, "de maneira a abrir um espaço próprio de fabulação." (id., op . cit., p. 33)

Essa competição, o agon, não será necessariamente consciente por parte do epígono, que age como age por puro ímpeto de sobrevivência, mas mesmo assim implicará na "melancolia da mente criativa, em sua desesperada insistência pela prioridade" (id., op. cit., p. 42). A-demais, postando-se o epígono diante da autoridade patriarcal de seus prógonos, como Édipo em face de Laio, a emulação "envolve imensas angústias de débito: pois que criador forte jamais desejaria a consciência de não se ter criado a si mesmo?" (id., op. cit., p. 33) Isto é: embora a única estratégia que lhe garanta o acesso ao panteão do cânone seja a originalidade, o autor novo tem que conviver com o fantasma da impossibilidade de uma originalidade absoluta, sob a ameaça contínua da repetição, o que põe em perigo de perempção até mesmo o eu enquanto eu poético e criador. Portanto, comenta Bloom,

A Influência Poética é o sentimento - espantoso, torturante, arrebatador - da presença de outros poetas nas profundezas do solipsista quase perfeito, ou poeta forte em potencial. Pois o poeta forte está condenado a descobrir suas ânsias mais profundas através da experiência de outros eus. O poeta traz seu poema dentro de si, mas deve passar pela vergonha e pelo esplendor de se ver achado pelos poemas - grandes poemas - exteriores a ele. Perder a liberdade nesse centro significa não ser nunca mais capaz de perdoar, e conhecer, para sempre, o terror de ver a própria autonomia ameaçada. (id., op. cit., p. 57; grifos do autor)

O candidato a poeta forte, por conseguinte, contra o peso da influência dos poetas fortes precursores (no sentido mesmo de "Influenza - uma doença astral"; id. op. cit., p. 133), cria freudianos "mecanismos de defesa", que Bloom enfeixa no que denominou "seis razões revisionárias" (id., op. cit., p. 42), seis estratégias de revisão criativa da tradição, as quais, resumi-damente, são as seguintes:

1. Clinamen, palavra encontrada por Bloom no atomismo de Lucrécio, representa a desleitura ("misreading") ou a desapropriação ("misprision") poética: o poeta promove, por meio de seu poema, em relação à prioridade e autoridade do poema do poeta precursor e mesmo em relação à prioridade e autoridade de toda a tradição poética herdada, um "desvio" (id., op. cit., p. 43), um "ato de correção criativa que é, na verdade, e necessariamente uma interpretação distorcida." (id., op. cit., p. 62; grifo do autor; sic) Vale 


\section{SEMINÁRIO DE PESQUISA EM CIÊNCIAS HUMANAS - SEPECH \\ Humanidades, Estado e desafios didático-científicos \\ Londrina, 27 a 29 de julho de 2016}

dizer: o efebo, para ter voz em liberdade, de-sautoriza a tradição a dar a última Palavra algo mais deveria ter sido dito pelos precursores, mas não o foi, lacuna de trabalho poético que cumpre preencher. O clinamen consiste na acusação, feita pelo poema aspirante, dessa lacuna e da falha dos prógonos.

2. Tessera, "a complementação e antítese", o trabalho em si de preenchimento da lacuna legada pela tradição. O termo foi colhido por Bloom em Jacques Lacan, que por sua vez tê-lo-ia emprestado de uma "tradição dos antigos mistérios religiosos, onde a reunião de dois pedaços quebrados de cerâmica servia como sinal de reconhecimento entre os iniciados" (explicação de Anthony Wilden, tradutor estadunidense de Lacan, apud id, op. cit., p. 103; grifei; sic). Por es-se "sinal de reconhecimento", o autor novo efetivamente atua para adentrar o recinto do cânone, ao trazer a complementação antitética, com seu poema, para "o significado" (id., op. cit., p. 106) de "algum poema essencial e de um precursor indubitável, mesmo que o efebo jamais te-nha lido esse poema." (id., op. cit., p. 107; grifo do autor) Em conclusão,

É nesse sentido de uma ligação de complementação que a tessera representa a tentativa, da parte do efebo, de se persuadir a si mesmo (e de nos persuadir) que a Palavra do precursor já estaria inteiramente desgastada se não redimida pela mais ampla e revigorada Palavra do novo poeta. (id., op. cit., p. 103; sic)

3. Kenosis, o "mecanismo de ruptura semelhante aos mecanismos de defesa empregados pela psiquê contra as compulsões de repetição" (id., op. cit., p. 43). O termo, cunhado por São Paulo, quer se referir à humildade de Jesus quando se esvazia de Sua divindade para dar lugar à Sua humanidade ${ }^{1}$. O efebo, como a reagir ao risco de um ritual transtextual $^{2}$ de transtorno obsessivo-compulsivo, instaura a "descontinuidade com relação ao precursor" (id., op. cit., p. 43) - é por aí que se vê que a noção de "influência", em Bloom, não tem qualquer interesse na mera citação, alusão, intertextualidade ou mimese de temas, imagens ou estilos de predecessores, mas sim sugere uma interpretação desapropriadora de um grande poema por parte de outro poema que aspira a ser grande. A desapropriação pretendida é a da "prioridade de se nomear alguma coisa pela primeira vez", a descoberta de uma fatia de universo até então desconhecida pelo ser humano - é a reclamação da prerrogativa adâmica de recriar culturalmente o universo natural e dele, já agora duplicado como universo natural e cultural, tomar posse: "Poetry is property" (BLOOM, 1997, p. 115). Assim, mediante a kenosis, Adão se esvazia de si para poder ser Deus, a criatura se esvazia de si para poder ser Criador, o Filho se esvazia de Si para poder ser o Pai, o epígono se esvazia de si para poder ser o prógono. Contudo, há que se levar em consideração: o si de Adão e da criatura, o $S i$ de Jesus e o do epígono, enfim, o si que lhes dá, a cada um, a força de criação poética, a Palavra, o Verbo e a Poesia porventura não lhes se-rá o mesmo Deus criador, o mesmo Pai e o mesmo prógono? Ladrão de fogo de olhar oblíquo e dissimulado, oculto na noite, à procura angustiada do isolamento de "sua identidade com relação à postura do precursor", cuja sombra incômoda e

\footnotetext{
${ }^{1}$ Embora, segundo me parece, Bloom não o tenha anotado, percebe-se uma semelhança da kenosis paulina com o tzimtzum da Cabala de Isaac Luria, sobre o que o teórico discorreria mais tarde, em Cabala e crítica (BLOOM, 1991b, p. 49 et passim).

${ }^{2}$ Cf. GENETTE, Gérard. Palimpsestes. Paris, Seuil, 1982.
} 


\section{SEMINÁRIO DE PESQUISA EM CIÊNCIAS HUMANAS - SEPECH \\ Humanidades, Estado e desafios didático-científicos \\ Londrina, 27 a 29 de julho de 2016}

imensa deve ser anulada, e ainda para se livrar de "uma transformação em tabu em e para si mesmo" (BLOOM, 1991a, p. 125),

O poeta posterior, aparentemente esvaziando-se de sua própria fabulação, sua própria divindade fabulatória, supostamente se torna humilde, como se estivesse deixando de ser poeta, mas a vazante é executada de tal forma em relação a um poema-de-vazante precursor que o precursor também se vê esvaziado, de modo que o segundo poema não é tão absoluto quanto parece. (id., op. cit., p. 44)

Oportuno anotar que "Freud enfatiza a relação entre os mecanismos de defesa e toda a área do tabu; no contexto que aqui nos concerne, deve-se notar a relevância, para a kenosis, de tabus de contato e limpeza" (BLOOM, 1991a, p. 125), exatamente como ocorre no transtorno obsessivo-compulsivo. Logo, o poema novo funciona, para o efebo, como terapêutica de resistência contra o transtorno da repetição inútil da tradição totêmica, sendo esse ato repetitivo en-tendido como um tabu, uma atitude proibida a ser terminantemente recusada em prol da originalidade.

4. Demonização: "um movimento na direção de um Contra-Sublime próprio, como reação ao Sublime do precursor"; segundo Bloom, "a palavra vem da tradição neoplatônica em geral, on-de um ente intermediário [o daimon], nem divino, nem humano, se incorpora ao adepto para auxiliá-lo." (id., ibid.; sic; colchetes do tradutor) O daimon ou demônio, aqui, deve ser entendido como a força psíquica, a qualidade espiritual necessária para que um efebo se torne um poeta forte ou, conforme o poeta Michael Drayton, "um grande e possante espírito, muito acima da fraqueza dos homens", "aquele que pela grandeza de sua mente aproxima-se dos Deuses" (id., op. cit., p. 138). Então, o poeta forte jamais é "possuído" pelo daimon, mas se torna, "ele mesmo" (id., ibid.), um daimon, a partir do momento em que se tornou forte, enquanto o poeta precursor tem a sua imagem enfraquecida e dissolvida; porque a demonização do epígono, sendo a sua divinação e individuação, implica na humanização temporária do prógono. ${ }^{3}$

5. Askesis ("ascese"), "autopurgação" ou "solipsismo" é a quinta razão revisionária proposta por Bloom, que buscou essa terminologia no que chama de "prática de xamanistas pré-socráti-cos, como Empédocles" (id., op. cit., p. 44), e corresponde, em grande medida, à sublimação e à catexia freudianas. Trata-se, fundamentalmente, de "uma autolimitação que busca a mudança, à custa de um estreitamento do círculo criativo tanto do precursor quanto do efebo." (id., op. cit., pp. 159-160) Nesse mecanismo, o poeta novo amadurece e mantém internalizada a sua agressividade contra a autoridade do poeta precursor e da tradição: fetichizado - Bloom diz mesmo "Intoxicado" (id., op. cit., p. 156) - pelo Contra-Sublime que operou e por sua própria força criadora, o efebo, agora se reconhecendo como um poeta forte, permite-se o luxo de conceder. Se, como Prometeu, ele dá o fogo do poema novo, como Narciso ele se contempla no poema, orgulhoso em meio ao incêndio que ateou - mas paga por essa contemplação: mais que Narciso, é enfim como Nero ou Heróstrato que se reconhece. Porque, quando o poeta percebe que enfim ascendeu à altura do prógono, de imediato percebe igualmente ter praticado o

\footnotetext{
${ }^{3}$ Bloom poderia ter utilizado a palavra "demonization", mais corrente, porém grafa outra palavra dicionarizada, "daemonization", assim enfatizando o elemento "daimon" e precavendo-se de quaisquer equívocos de associação com "demon" - s. m. j., talvez o tradutor brasileiro, com igual intento, pudesse ter usado, ainda que constitua um preciosismo em nossa língua, "daimonização".
} 


\section{SEMINÁRIO DE PESQUISA EM CIÊNCIAS HUMANAS - SEPECH \\ Humanidades, Estado e desafios didático-científicos \\ Londrina, 27 a 29 de julho de 2016}

pecado de iconoclastia e mais até: percebe que desde agora é o seu próprio prógono e, portanto, pa-ra manter-se como poeta forte, terá que voltar a sanha iconoclástica contra si mesmo. Angústia das angústias, no último lance de imagem o poeta é Ícaro: sua subida é a causa de sua queda. Como o precursor, é mais uma estátua a ser quebrada, e a certeza da ruína é o único consolo possível para tal angústia, vez que "o precursor é louvado por ter sido precisamente aquilo em que o poeta já se transformou." (id., op. cit., p. 167; grifo do autor) Decerto esta é a mais complexa e paradoxal razão de defesa identificada por Bloom, o supremo orgulho disfarçado em modéstia: "Whitman, em Crossing Brooklyn Ferry, vê o pôr-do-sol, o fluxo das cheias, o refluxo da vazante de volta ao mar' e se consola na idéia de que outros virão, para ver o que e co-mo ele vê." (id., op. cit., p. 174) Eis talvez o motivo pelo qual o crítico considera que "a poesia moderna mais forte é criada pela askesis" (id., op. cit., p. 177).

6. Apophrades é "o retorno dos mortos": a palavra, na antiga Atenas, designava os "dias infaustos, dias de má sorte, quando os mortos (...) voltavam a habitar a casa onde haviam vivido." (id., op. cit., p. 44) No caso, são os prógonos que vêm assombrar o poeta novo em vias de se tornar forte, o qual teme ser transportado "de volta aos dias sufocantes de seu aprendizado, antes que sua força tivesse começado a se fazer sentir nas razões revisionárias." No entanto, "o sucesso do novo poema", como num exorcismo, faz com que o sucessor aproprie-se da tradição e sinta-se como se ele próprio tivesse criado "a obra característica" (id., op. cit., p. 45) de seu precursor. O que quer dizer: teria sido a sua interpretação do poema antigo, conflagrada no poema recente, que conferiu àquele o significado alcançável mais verdadeiro. No concerto, "é possível crer, por alguns momentos surpreendentes, que estão, eles mesmos [os efebos que fi-caram fortes], sendo imitados por seus ancestrais." (id., op. cit., p. 183) Por isso, não se cuida, Bloom alerta, de conceito semelhante àquele exposto por Jorge Luis Borges no ensaio "Kafka y sus precursores" - a bem dizer, são conceitos em princípio irreconciliáveis, dado que, para o argentino,

En el vocabulario crítico, la palabra precursor es indispensable, pero habría que tratar de purificarla de toda connotación de polémica o de rivalidad. El hecho es que cada escritor crea a sus precursores. Su labor modifica nuestra concepción del pasado, como ha de modificar el futuro. (BORGES, 1984, pp. 711-712; grifos do autor)

Para Borges, o epígono forte cria os seus próprios prógonos, ao estabelecer novos padrões estéticos que, alterando a recepção do cânone, permitem que neles possam ser percebidas afinidades antes insuspeitadas, alguma particularidade em comum que, se o epígono "no hubiera escrito, no la percibiríamos" (id., op, cit., p. 711) Já nos apophrades de Bloom, o epígono, para se ver como prógono, recria seus prógonos como se fossem epígonos; estando vivo e seus precursores mortos, "determinadas passagens" das obras destes lhe parecem "não presságios do advento do efebo, mas sim conseqüentes e em débito com este, e mesmo (necessaria-mente) diminuídas pelo esplendor maior do novo poeta." (BLOOM, 1991a, p. 183) Na resistên-cia ao instante infausto e repressivo em que os grandes mortos representam querer regressar e outra vez atormentá-lo, o efebo os desapropria daquilo que mais o atemoriza: a originalidade. A individuação viva repele qualquer identificação com os mortos, atitude de extrema arrogância, sem a qual o efebo não sobreviveria enquanto poeta. A arrogância, sob essa perspectiva de Bloom, 


\section{SEMINÁRIO DE PESQUISA EM CIÊNCIAS HUMANAS - SEPECH \\ Humanidades, Estado e desafios didático-científicos \\ Londrina, 27 a 29 de julho de 2016}

é a ambrosia de todo poeta forte - e quem sabe o crítico concordasse que, na "Carta do vidente", as diatribes juvenis de Arthur Rimbaud contra toda a poética ocidental, no período de "dois mil anos" que vai "Da Grécia ao movimento romântico - Idade Média", constituem um claro exemplo não de apophrades, mas da postura arrogante que é o seu necessário substrato: "Quanto ao mais, liberdade aos novos! de execrar os ancestrais: estamos em casa e temos tempo." (RIMBAUD, 2009, p. 38; grifo do autor) De todo modo, Bloom ainda argumenta que "o tema oculto da maior parte da poesia dos últimos três séculos tem sido a angústia da influência, o medo de todo poeta de que não haja nada mais para ser feito." (BLOOM, 1991a, p. 190) Por consequência, o "medo" the anxiety of influence - seria o grande motor da poética moderna.

\section{ALEGRIA ANTROPOFÁGICA}

Os primeiros esboços do conceito de antropofagia foram estabelecidos por Oswald de Andrade em 1924, com o Manifesto da Poesia Pau-Brasil, cujas linhas mestras foram o conclame renovador rumo à "poesia de exportação" (ANDRADE, 1971, p. 95) e ao "primitivismo nativo" (que o poeta consideraria "nosso único achado de 22"; id., ibid., p. 96). Na esteira dessas linhas, o conceito foi mais bem delineado com o Manifesto antropófago (às vezes dito "antropofágico"), de 1928; porém, Oswald ainda o trabalharia por décadas, em textos ora curtos, como os artigos que compõem a série $A$ marcha das utopias (1953), ora longos, como A crise da filosofia messiânica (1950), sua tese de Livre-docência. No início, a antropofagia oswaldiana provavelmente não queria ser senão um programa de revitalização estética da literatura e da cultura brasileiras, mas aos poucos foi assumindo "foros de uma autêntica Weltanschau-ung" (id., 2011, p. 82), vasto complexo órfico que abrange, além das ocupações estéticas, também preocupações éticas, étnicas, sócio-políticas, filosóficas e religiosas (embora este último e relevante aspecto seja costumeiramente negligenciado pela fortuna crítica do autor). Sob esse prisma, pode-se dizer que a antropofagia se configura, em sua acepção mais ampla, como uma instrumentalização teórica para a prática efetiva da utopia: em termos extremamente sinópticos, Oswald divisa uma sociedade humana anterior, primeva, fruto do regime do Matriarcado, na qual predominava "uma cultura antropofágica" (id., op . cit., p. 139), polígama e libertária, que assegurava a todo indivíduo o direito ao Ócio, sob as benesses da Deusa-Mãe. Entretanto, essa sociedade matriarcal foi derrubada, e em seu lugar surgiu a sociedade moderna, em torno de um regime do Patriarcado, o qual impôs "uma cultura messiânica" (id., ibid.), monógama e escravocrata, a fim de atender aos interesses de elites proprietárias, sustentadas sobre o Sacerdócio, que é o "ócio sagrado", isto é, interdito ao cidadão comum, e o Negócio, "que é a negação do ócio" (id., op, cit., p. 178), em nome do lucro; o Sacerdócio corresponde ao poder temporal-espiritual que institucionalizou a figura severa do Deus-Pai castigador; e o Negócio, ao poder secular que institucionalizou a figura desonesta do patrão explorador. Não é difícil detectar, nos vários componentes desse sistema, o desdobrar de uma matriz ideológica que, dentre outros pensadores, partiu de Johann Jakob Bachofen, Karl Marx, Friedrich Engels e, conquanto Oswald não o mencione, Paul Lafargue. Entrementes, Oswald compreende como dialética a passagem histórica da autoridade matriarcal à autoridade patriarcal: no " 1 o termo: tese - o homem natural" tem as suas prerrogativas de canibal, vivendo a mágica da liberdade; no " 2 o termo: antítese - o homem civilizado" vive sob 


\section{SEMINÁRIO DE PESQUISA EM CIÊNCIAS HUMANAS - SEPECH \\ Humanidades, Estado e desafios didático-científicos \\ Londrina, 27 a 29 de julho de 2016}

uma lógica da primazia do capital sobre o indi-víduo, mas realizou o progresso tecnológico; e o que virá em seguida é um utópico " 3 ” termo: síntese - o homem natural tecnizado" (id., op. cit., p. 141), tão logo liberado de todo trabalho, por conta da invenção e disseminação da máquina para atender a todas as necessidades humanas, poderá retornar ao estado matriarcal, gozando agora o mais absoluto otium cum dignitate.

Recorde-se que por dentro dessa antropofagia em acepção ampla, como pauta teórica de utopia, está a raiz fundante da antropofagia em sentido estrito, como atitude prática de entropia. Oswald retoma do nosso indianismo romântico a proposição do indígena como símbolo da originalidade étnica e da identidade sócio-cultural brasileira e, no entanto, essa retomada se dá numa clave de profunda e ousada reformulação. Conforme bem observa Haroldo de Campos, no ensaio "Uma poética da radicalidade",

O "índio" oswaldiano não era o "bom selvagem" de Rousseau, acalentado pelo Romantismo e, entre nós, "ninado pela suave contrafação de Alencar e Gonçalves Dias". Tratava-se de um indianismo às avessas, inspirado no selvagem brasileiro de Montaigne (Des Cannibales), de um "mau selvagem", portanto, a exercer sua crítica (devoração) desabusada contra as imposturas do civilizado ${ }^{4}$. (CAMPOS, 1974, pp. 4950; grifo do autor)

O que, sobretudo, interessa a Oswald é o ethos brasilíndio pré-cabralino segundo o qual a devoração cerimonial da carne do inimigo valoroso, capturado em batalha, tem o condão de transmitir as qualidades desse indivíduo - como a força, a coragem, a destreza - ao antropófago que o subjugou, mata e consome. Sem préstimo, então, a noção da antropofagia tosca, prati-cada "por gula ou por fome" ou vã violência e acusadoramente associada à "baixa antropofagia aglomerada nos pecados capitais do catecismo a inveja, a usura, a calúnia, o assassinato. Peste dos chamados povos cultos e cristianizados, é contra ela que estamos agindo. Antropófa-gos." (ANDRADE, 2011, p. 74) O quid oswaldiano se dedica à antropofagia como ritual mági-co investido de um "sentido harmônico e comunal" e que "pertence como ato religioso ao rico mundo espiritual do homem primitivo." (id., op. cit., , p. 138). Porque (apropriando-se da terminologia freudiana)

A operação metafísica que se liga ao rito antropofágico é a da transformação do tabu em totem. Do valor oposto, ao valor favorável. A vida é de-voração pura. Nesse devorar que ameaça a cada minuto a existência humana, cabe ao homem totemizar o tabu. Que é o tabu senão o intocável, o limite? (id., op. cit., p. 139)

Com apoio em Homero, Blanco Villalta e outros, Oswald assevera que a antropofagia, como rito religioso, esteve presente transistoricamente em todo o planeta e entre povos de cultura sofisticada, a exemplo dos gregos antigos, os astecas, os maias e os incas. O uso progressi-vamente foi se perdendo com o declínio do Matriarcado primiti

\footnotetext{
${ }^{4}$ É conveniente reproduzir a nota de rodapé que Campos acrescenta nessa passagem: "Esta 'apologia do papão in-dígena', na expressão de ROGER BASTIDE, ao influxo do 'caráter internacional, ocidental, moderno, de São Paulo', desborda da simples 'renovação do indianismo', colorindo-se 'de freudismo ou de marxismo conforme a é-poca' (Brasil Terra de Contrastes, tradução brasileira, São Paulo, Difusão Européia do Livro, 1959, p. 202)."
} 


\section{SEMINÁRIO DE PESQUISA EM CIÊNCIAS HUMANAS - SEPECH \\ Humanidades, Estado e desafios didático-científicos \\ Londrina, 27 a 29 de julho de 2016}

vo, tendo permanecido, porém, nas visões de mundo e nos padrões culturais de certos povos, contando-se aí as nações bárbaras da primitiva Terra Brasilis. A chegada do europeu, armado de arcabuzes, de machados e da parenética da catequese messiânica, significou a repressão e a transformação em "tabu" desse importante "totem" da cultura brasílica: "Antes dos portugueses descobrirem o Brasil, o Brasil tinha descoberto a felicidade." (id., op. cit., p. 72)

"Mas não foram cruzados que vieram. Foram fugitivos de uma civilização que estamos comendo, porque somos fortes e vingativos como o Jabuti" (id., op., cit., p. 71) - e o iauaretê. Oswald afirma que o espírito antropofágico, "O instinto Caraíba" (id., op. cit., p. 70), persiste entranhado no coração mesmo da identidade brasileira, pois, sob o verniz de civilidade dos co-roinhas, mascates, bacharéis, de fato "nunca admitimos o nascimento da lógica entre nós" (id., op. cit., p. 69) e "Nunca fomos catequizados. Fizemos foi Carnaval" (id., op. cit., p. 70) e "Fizemos Cristo nascer na Bahia. Ou em Belém do Pará." (id., op. cit., p. 69) A chegada do africa-no, com seu pensamento selvagem irmanado com o pensamento selvagem indígena, teria inclusive auxiliado nesse processo de sobrevivência. O resultado de tudo é que o ímpeto antropofágico constituiria, com efeito, o traço distintivo a definir a brasilidade: "Só a antropofagia nos une. Socialmente. Economicamente. Filosoficamente." (id., op. cit., p. 67) Em decorrência, Oswald propõe o reconhecimento pleno da personalidade brasileira e o caminho de regresso que, paradoxal e dialeticamente, conduz ao futuro: "A transformação permanente do Tabu em totem." (id., op. cit., p. 69) E, gostosamente comendo William Shakespeare, "No país da cobra grande" (id., op. cit., p. 68), do Pau-Brasil: "Tupi, or not tupi that is the question." (id., op. cit., p. 67; sic)

O projeto antropofágico de Oswald, herdeiro renitente do projeto magalhanesco, gonçalvino e alencariano de construção da brasilidade, não se exaure no litoral atlântico. Oswald define a "Lei do antropófago" como a verdadeira "Lei do homem", "Única lei do mundo." (id., ibid.) E, embora o poeta se declare "Contra o Padre Vieira" (id., op. cit., p. 69), é inegável no discurso do Manifesto antropófago a admissão de um tom milenarista que, derrogando à primazia do Quinto Império por um Portugal devorado no festim "da Deglutição do Bispo Sardinha" (id., op. cit., p. 74; grifo do autor), demanda a pregação de um humanista evangelho tupinambá ou timbira (cf. " $Y$-juca-pirama"): "Queremos a revolução Caraíba. Maior que a Revolução Francesa. A unificação de todas as revoltas eficazes na direção do homem. Sem nós a Eu-ropa não teria sequer a sua pobre declaração dos direitos do homem. A idade de ouro anunciada pela América. A idade de ouro." (id., op. cit., p. 68) A postulação de Oswald se justifica por uma circunstância facilmente esquecida pelos livros de História, quase sempre orientados por uma visão eurocêntrica: a redescoberta da América pelos europeus trouxe ao fatigado e Velho Mundo o choque da visão de uma nova possibilidade de redenção do humano. Em particular, o Hy Breasail $^{5}$ desnudo, luxuriante, pujante, limpo, preguiçoso, rubro de saúde - edênico - trouxe à mente ainda medieval do europeu desdentado de escorbuto o aceno de outra oportunidade de, como Jacó, vencer a espada flamante do terrível Uriel. Se a pusilanimidade da pólvora ven-ceu o curare da flecha, a artrítica Europa não ficou totalmente imune e se beneficiou do bálsamo americano, com vistas à inquietação iluminista e seus sucedâneos:

\footnotetext{
${ }^{5}$ V. a "Introdução" a CARVALHO, Ronald de. Pequena História da Literatura Brasileira. 6a ed. Pref. Medeiros e Albuquerque. Rio de Janeiro, F. Briguiet \& C., 1937.
} 


\title{
XI SEMINÁRIO DE PESQUISA EM CIÊNCIAS HUMANAS - SEPECH \\ Humanidades, Estado e desafios didático-científicos \\ Londrina, 27 a 29 de julho de 2016
}

Filiação. O contato com o Brasil Caraíba. Où Villegaignon print terre. Montaigne. O homem natural. Rousseau. Da Revolução Francesa ao Romantismo, à Revolução Bolchevista, à Revolução surrealista ${ }^{6}$ e ao bárbaro tecnizado de Keyserling. Caminhamos. (id., op. cit., pp. 68-69)

Adicione-se a isso o surpreendente brilho aurífero da antiga Civilização Asteca e dos Impérios Maia e Inca, o mito de Eldorado e a fascinante robustez das demais nações originári-as norte-americanas. A arguta visão de Oswald aponta para o óbvio: ao redescobrir a América, a Europa envelhecida redescobriu-se. É nesse contexto que Oswald se coloca "Contra a realidade social, vestida e opressora, cadastrada por Freud - a realidade sem complexos, sem loucura, sem prostituições e sem penitenciárias do matriarcado de Pindorama." (id., op. cit., p. 74)

Mister esclarecer que o provocativo ideário oswaldiano pressupõe, sob risco de parecer anacrônico, a atualização filosófica do primitivo elã antropofágico. Modernamente, tem-se em perspectiva a

\begin{abstract}
Absorção do inimigo sacro. Para transformá-lo em totem. A humana aventura. A terrena finalidade. Porém, só as puras elites conseguiram realizar a an-tropofagia carnal, que traz em si o mais alto sentido da vida e evita todos os males cadastrados por Freud, males catequistas. O que se dá não é uma sublimação do instinto sexual. É a escala termométrica do instinto antropofágico. De carnal, ele se torna eletivo e cria a amizade. Afetivo, o amor. Especulativo, a ciência. (id., op. cit., p. 73)
\end{abstract}

O alvo final é a pura plenitude da paz para o ser humano, ensejada pela moral antropofágica brasileira: "A alegria é a prova dos nove." (id., ibid.)

Dessa maneira, a filosofia antropofágica oswaldiana se constitui como um arsenal teórico sólido, apto a propor subsídios para a abertura de muitas frentes de reflexão nos diversos horizontes das Humanidades. O lastro que proporciona para uma melhor compreensão e para a contínua atualização da literatura e da cultura brasileiras não se esgotou com a geração heróica do nosso Modernismo: movimentos dos mais importantes de nossa inteligência, como a Bossa Nova, o Concretismo e seus desdobramentos, a Jovem Guarda, a Tropicália, o Brock desde os anos 80, a Poesia Marginal aproveitaramse, em grande medida, dos preceitos de Oswald. Várias das obras mais robustas de nossos autores do séc. XX e XXI foram direta ou indiretamente influenciadas pela antropofagia oswaldiana, na Poesia, na prosa, no teatro, na música e em ou-tras áreas, caso de, aleatoriamente falando, Carlos Drummond de Andrade, João Cabral de Me-lo Neto, Vinicius de Morais, Manoel de Barros, Guimarães Rosa, Osman Lins, Ariano Suassuna, José Celso Martinez Corrêa, Heitor Villa-Lobos, Noel Rosa, Tom Jobim, Tom Zé, Caetano Veloso, Paulo Leminski, Arnaldo Antunes, Glauber Rocha, Burle Marx, Hélio Oiticica.

A antropofagia, contudo, não se restringe ao cenário brasileiro. Conforme diz o crítico João Cezar de Castro Rocha, é preciso "entender a antropofagia como um exercício de pensamento cada dia mais necessário nas circunstâncias do mundo globalizado,

\footnotetext{
${ }^{6}$ Antecipada em dois anos pelo "Prefácio interessantíssimo" do antropófago Mário de Andrade.
} 


\section{SEMINÁRIO DE PESQUISA EM CIÊNCIAS HUMANAS - SEPECH \\ Humanidades, Estado e desafios didático-científicos \\ Londrina, 27 a 29 de julho de 2016}

pois a antropofagia permite que se desenvolva um modelo teórico de apropriação da alteridade." (ROCHA, 2011, p. 12; grifei) Por via de conseqüência, "A teoria oswaldiana exige uma releitura antropológica da antropofagia. Releitura que, pela própria dinâmica do olhar antropológico, ultrapassa fronteiras nacionais, oferecendo um modelo fecundo para refletir sobre a transmissão de valores em situações culturais assimétricas." (id., op. cit., p. 13) Sendo uma dialética da apropriação do ou-tro pelo eu, trata-se de ferramenta de larga utilidade para considerações sobre temas importantes da contemporaneidade, por exemplo, colonialismo e neocolonialismo, estudos culturais e identidade: ver o outro no eu, ver o eu no outro, porque é certo que, na ética selvagem, todo an-tropófago está a toda hora sujeito a virar repasto - a bem dizer, nessa ética devorar é uma honra, e ser devorado, o que implica em reconhecimento de valor, não é honra menor. Rocha ainda declara que, "se o grande dilema contemporâneo é inventar uma imaginação teórica capaz de processar a vertigem de dados recebidos ininterruptamente, então, a antropofagia oswaldiana pode tornar-se uma alternativa relevante para a redefinição da cultura contemporânea." (id., op. cit., pp. 13-14)

Aplicando-se esse "modelo teórico de apropriação da alteridade" ao campo da influência, a recepção desta passa a ser entendida como absolutamente apropriativa: o antropófago - o epígono - toma posse daquilo que é seu por direito de combate, "sem complexos, sem loucura, sem prostituições e sem penitenciárias", sem "a inveja, a usura, a calúnia, o assassinato", e de-vora o espólio cultural do prógono, de toda a tradição canônica, digerindo-o criticamente numa atitude de "invenção" e "surpresa" (ANDRADE, 2011, p. 63) e de perfeita alegria selvagem. Devorar o outro é reconhecer o valor do outro no que tem de melhor e se apropriar desse valor em benefício da sobrevivência do $e u$ - como direito natural do vivo, e não como furto ou violência. É o ritual da vida, em que até as cinzas dos ossos da quarta-feira são devoradas: festim da tribo, carnaval canibal.

\section{REFERÊNCIAS BIBLIOGRÁFICAS}

ANDRADE, Oswald. Ponta de lança (Obras completas 5). $2^{\mathrm{a}}$ ed. Rio de Janeiro, Civilização Brasileira, 1971. . A utopia antropofágica. $4^{\mathrm{a}}$ ed. São Paulo, Globo, 2011.

BLOOM, Harold. A anatomia da influência - Literatura como modo de vida. Trad. Ivo Kory-towski e Renata Telles. Rio de Janeiro, Objetiva, 2013.

. A angústia da influência - Uma teoria da Poesia. Trad. e apres. Arthur Nestrovski. Rio de Janeiro, Imago, 1991a.

The anxiety of influence - A theory of Poetry. $2^{\text {nd }}$ ed. New York, Oxford, 1997.

Cabala e crítica. Trad. Monique Balbuena. Rio de Janeiro, Imago, $1991 b$.

BORGES, Jorge Luis. Obras completas - 1923-1972. 14ª ed. Buenos Aires, Emecé, 1984. 


\section{SEMINÁRIO DE PESQUISA EM CIÊNCIAS HUMANAS - SEPECH \\ Humanidades, Estado e desafios didático-científicos}

Londrina, 27 a 29 de julho de 2016

CAMPOS, Haroldo de. "Uma poética da radicalidade". In: ANDRADE, Oswald de. Poesias reunidas (Obras completas 7). 4 ed. Rio de Janeiro, Civilização Brasileira, 1974.

ROCHA, João Cezar de Castro. "Oswald em cena: o Pau-Brasil, o Brasileiro e o Antropófago". In: RUFFINELI, Jorge; e ROCHA, João Cezar de Castro (org.). Antropofagia hoje? São Paulo, É Realizações, 2011. 